\title{
Thermal Stability of Titanium Alloy VT8M-1 with Ultrafine-Grained Structure
}

\author{
A.G. Stotskiy*, A.V. Polyakov, G.S. Dyakonov, I.P. Semenova
}

Institute of Physics of Advanced Materials, Ufa State Aviation Technical University, 450591, Ufa, Republic of Bashkortostan, Russian Federation

*Corresponding author: stockii_andrei@mail.ru

\section{$\underline{\text { Abstract }}$}

The paper considers the effect of a long-duration heating at a service temperature of $450^{\circ} \mathrm{C}$ on VT8M-1 with a coarse-grained (CG) and ultrafine-grained (UFG) microstructure. A duplex ultrafine-grained microstructure, composed of equiaxed grains of primary $\alpha$-phase and an ultrafine constituent of $\alpha$ - and $\beta$-phases, was processed by thermal treatment and further rotary swaging. This type of a microstructure demonstrates a best combination of strength and ductility at room temperature in comparison with the CG structure. A thermal stability of an UFG state was studied at $450^{\circ} \mathrm{C}$ for $50,100,200,300,400$, and 500 hours. The evolution of the alloy microstructure against the duration of heating was considered by transmission electronic microscopy (TEM), scanning electronic microscopy (SEM). No increase in the alloy structural elements and strength decrease resulting from a long-term annealing (up to 500 hours) at $\mathrm{T}=450^{\circ} \mathrm{C}$ have been observed. This proves a high thermal stability of the UFG structure and mechanical properties of VT8M-1 processed via rotary swaging.

Keywords: Ti alloys, rotary swaging, ultrafine-grained structure, mechanical properties, long-term annealing, thermal stability.

\section{Introduction}

Two-phase $(a+\beta)$ Ti alloys that perform well within a wide temperature range are used to produce a number of critical parts both in aircraft engineering and engine manufacturing. In particular, VT8M-1 (Ti-5.7Al-3.8Mo-1.2Zr-1.3Sn), which is used to produce blades for a gas-turbine compressor (GTC), can be operated within a temperature range of $450-500{ }^{\circ} \mathrm{C}$. The service conditions of modern constructions are currently increasingly demanding, while applied thermal or thermomechanical treatment (TMT) cannot provide the necessary strength of part [1,2]. One of the most promising technique to enhance the mechanical properties of metallic materials is the formation of a bulk ultrafine-grained (UFG) structure via severe plastic deformation (SPD) methods [3]. It has been shown earlier that the formation of UFG structure in two-phase Ti alloys (with Ti-6Al-4V as an example) leads to the increase in specific strength, fatigue resistance, and the enhancement in service properties of parts made of such materials [4]. However, UFG metals processed via SPD often demonstrate a reduced thermal stability arising from a high accumulated internal energy, which leads to a fast relaxation and decreases the recrystallization temperature [5]. As a result, the practical application of UFG Ti alloys at a service temperature of GTC parts is seriously limited.

It is well known that during rotary swaging billets are slightly reduced in a gradual manner, which enables to achieve a higher strain degree in the material along with a more homogeneous deformation of a billet [6]. As a result, an UFG structure is formed in a bulk billet from VT8M-1, which is reported in [7]. The possibility to produce long-sized semi-finished parts supporting further shape-generating operations is another advantage of this technique. The goal of this work is to research a thermal stability of UFG structures at a service temperature and mechanical properties of VT8M-1 processed by a rotary swaging with a view to assess the innovative capacity of the material in terms of its usage for GTC production.

\section{Materials and methods}

VT8M-1 Ti alloy was taken as a study material. The chemical composition of the alloy is shown in Table 1. Hot-rolled rods 70 mm in diameter were considered as an as-delivered state. The material was produced by VSMPO-AVISMA Company (Verkhnaya Salda, Russian Federation). Rods were obtained by a vacuum-arc melting. The initial material was annealed at $750^{\circ} \mathrm{C}$ for 1 hour (TT) in order to obtaining an equilibrium duplex structure.

Table. 1. The chemical composition of VT8M-1 according to the Manufacturer's Certificate (weight, \%)

\begin{tabular}{|c|c|c|c|c|c|c|c|c|c|c|c|}
\hline $\mathrm{Ti}$ & $\mathrm{Al}$ & Mo & $\mathrm{Zr}$ & Sn & $\mathrm{Si}$ & $\mathrm{Fe}$ & $\mathrm{C}$ & $\mathrm{N}$ & $\mathrm{O}$ & $\mathrm{H}$ & Impurities \\
\hline 87.86 & 5.27 & 4.00 & 1.20 & 1.26 & 0.20 & 0.034 & 0.007 & $<0.003$ & 0.085 & 0.0021 & 0.1094 \\
\hline
\end{tabular}

Rotary swaging took place at $750^{\circ} \mathrm{C}$ with a gradual reduction along the diameter of billets from 70 to $32 \mathrm{~mm}$. As a result, true strain of 1.56 was reached. Strain degree was calculated from the following ratio: $e=\ln \left(S_{0} / S_{1}\right)$, where $S_{0}$ and $S_{1}$ are cross-section areas prior and after deformation, correspondingly.

To study thermal stability, coarse-grained VT8M-1 samples processed by TT (hereinafter referred to as CG) and by TT + rotary swaging (hereinafter referred to as RS) were held in a furnace at $450^{\circ} \mathrm{C}$. Continuous long-term annealing took place in furnaces produced by Noberterm Company. Holding time was 50 , $100,200,300,400$, and 500 hours.

Tensile mechanical tests were performed using Instron universal testing machine at room temperature with a strain rate of $1 \times 10^{-3} \mathrm{~s}^{-1}$, according to ISO 6892-1-2009. Cylindrical specimens cut out in the longitudinal direction were tested.

The microstructure in various states was studied both in longitudinal and cross-sectional directions using JEOL JSM 6390 scanning electron microscope and JEOL JEM 2100 transmission electron microscope. Samples for TEM-foils were cut out using electrical discharge machining, mechanically thinned to a thickness of $100 \mu \mathrm{m}$ and then electro-polished using a TenuPol-5 facility with a solution of $5 \%$ perchloric acid, $35 \%$ butanol and $60 \%$ methanol, at a polishing temperature within the range from -20 to $-35^{\circ} \mathrm{C}$.

The X-ray diffraction (XRD) analysis was conducted on a Rigaku Ultima IV diffractometer. The samples were examined with CuKa-radiation (40 kV, $30 \mathrm{~mA}$ ) and the phase composition of the alloy was determined using the Rietveld method.

(C) The Authors, published by EDP Sciences. This is an open access article distributed under the terms of the Creative Commons Attribution License 4.0 (http://creativecommons.org/licenses/by/4.0/). 


\section{$\underline{\text { 3. Results and discussion }}$} $a_{\mathrm{glob}} \approx 65 \%$.

VT8M-1 processed by TT has a duplex microstructure (Fig. 1a). A mean grain size in a CG state of a primary a-phase is about $3 \mu \mathrm{m}$ with a volume fraction
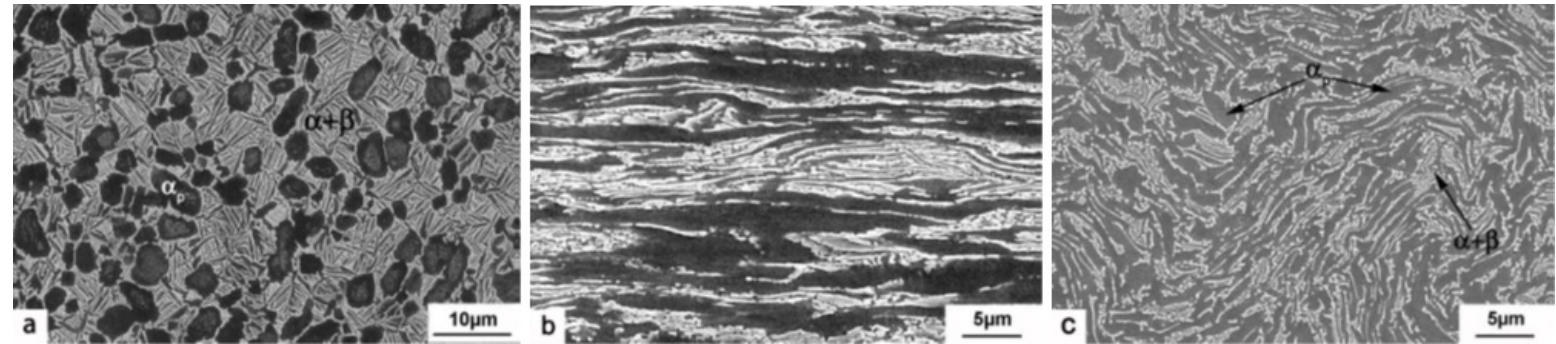

Fig. 1. VT8M-1 rod microstructure: (a) a coarse-grained state processed by TT in a cross section; (b) processed by a rotary forging both in longitudinal and (c) cross sections

Upon RS, the material microstructure is explicitly oriented along the axial direction (Fig. 1b), which is associated with the flow of the material during a RS. a-globules are elongated in the longitudinal section (Fig. 1b), and are twisted quite a lot in the cross section (Fig. 1C). The lamellar constituent upon deformation is divided into the fragments of oval and globular shapes. However, this process is rather heterogeneous with both almost unaffected laminas and strongly fragmented areas (which used to be integral laminas) observed.

The tensile mechanical testing of VT8M-1 in a CG state and after RS at room temperature shows an increase by $20 \%$ in the ultimate tensile strength in the RS-processed state as compared to a CG one (i.e. by $200 \mathrm{MPa}$ ) and constituted $1290 \mathrm{MPa}$, and a decrease by $5 \%$ in the elongation as compared to a CG state constituting $d=9 \%$. Also, it should be noted that a uniform elongation in the material after RS changed slightly making up about $3.4 \%$ (Fig. 2). In a recent work, the ultrafine-grained structure in VT8M-1 was obtained by ECAP [7]. These specimens demonstrated a slight (about 1,2\%) uniform elongation and rather rapid strain localization typical for many SPD-processed metals. It is reasonable to expect that the material subjected to RS has a higher fracture toughness compared to the ECAP-processed state.

By comparing the microstructure in CG and RS states subjected to a long-term annealing for 500 hours, it can be seen that annealing has almost no effect on the structure morphology and element dimensions (Fig. 1 and 3 ). Volume fraction $a_{p}$ remained at the level of $65 \%$ (Fig. 4$)$ with a similar mean size of $a_{\text {glob }}(3 \mu \mathrm{m})$. The same

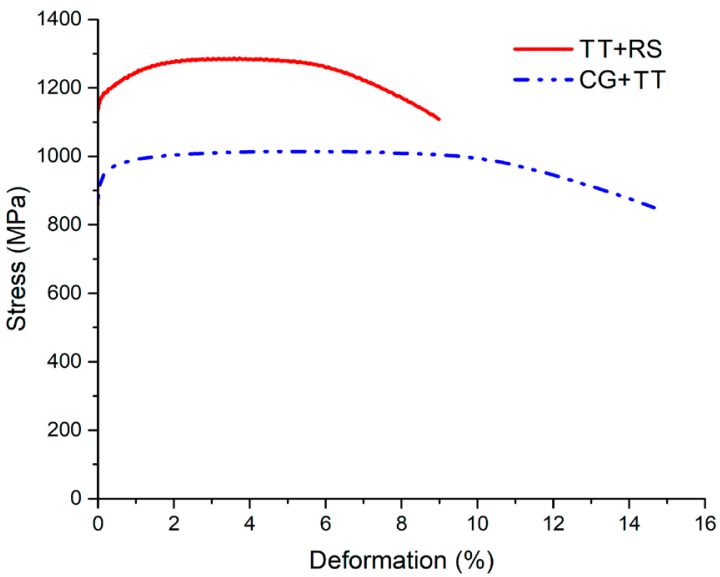

Fig. 2. Tensile curves of the VT8M-1 alloy in the CG and RS states at room temperature

picture was observed in an UFG state of VT8M-1 with grain size of primary a-phase and its volume fraction being at the same level after 500 hour heating (Fig. 3 and 4).
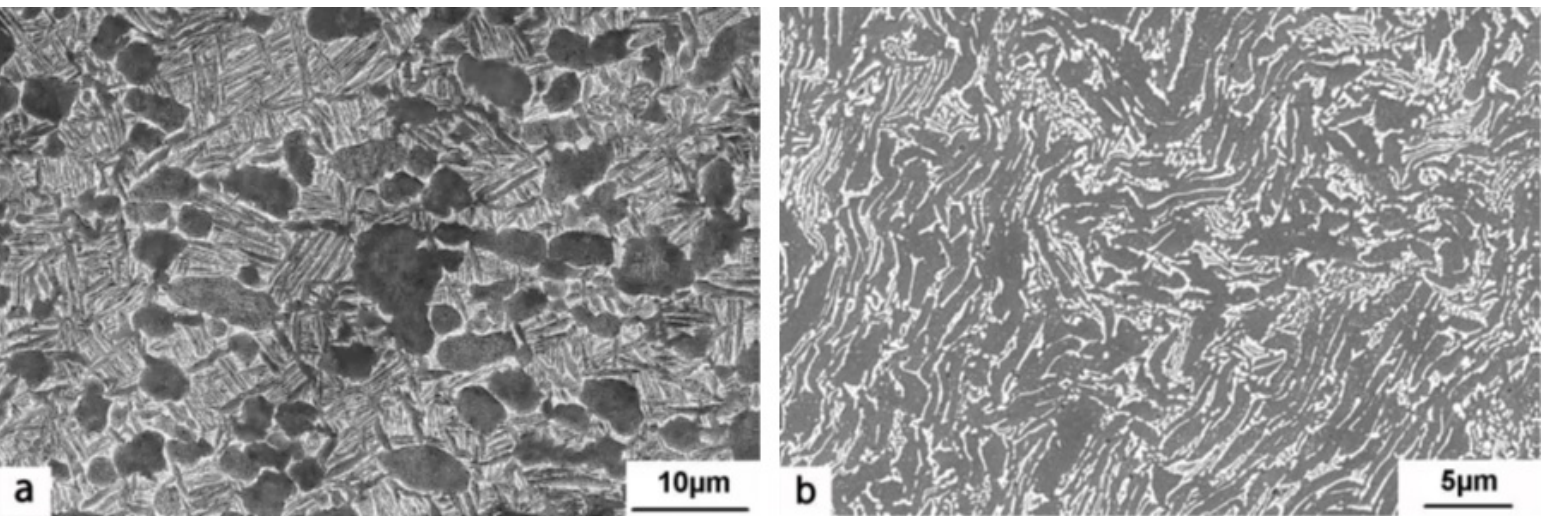

Fig. 3. Microstructure of VT8M-1 in a CG $(a-500 h)$ and RS-processed states $(b-500 h)$ in the cross section after long-term annealing at $450^{\circ} \mathrm{C}$

TEM method was applied to study the microstructure after annealing at $450^{\circ} \mathrm{C}$ with a holding time of 50,300 , and 500 hours more thoroughly (Fig. 5 ). RS processing resulted in an increased density of both grain-boundary and intragranular dislocations leading to less distinct interphase boundaries. The resulting microstructure has the combination of a lamellar constituent retained after deformation (with a thickness of lamellas of about $150 \mathrm{~nm}$ ) and grains as small as 300 $\mathrm{nm}$ of an oval shape. Such grains appeared during the formation of a cross interphase boundary, which resembles the fragmentation of lamellas. Local contractions with the formation of cross boundaries suggest that the fragmentation of lamellas take place by the mechanisms of groove formation and propagation. 
The annealing for 50 hours at $450^{\circ} \mathrm{C}$ led to the decrease in dislocation density with clearly distinct boundaries of lamellas and grains as a result of dislocation redistribution and annihilation. The longer holding duration (up to 300 and 500 hours) gave rise to recovery processes as well as to the generation of some more perfect grain boundaries (marked with the arrow in Fig. 5). The appearance of moire contouring of such grains points to a low level of internal stress.

A mean cross lamella dimension remains at the level of $150 \mathrm{~nm}$ with a grain size about $300 \mathrm{~nm}$. The analysis of TEM microstructure images of the annealed alloy conforms well to the X-ray results (Tab. 2). In particular, dislocation density fell from 10.8 to $7.5 \times 10^{15} \mathrm{~m}^{-2}$ and crystallite size increased from 25 to $41 \mathrm{~nm}$ resulting from the longer duration of annealing up to 100 hours (Tab. 2).

Closer examination of the fine microstructure of samples subjected to RS + annealing for $300 \mathrm{~h}$ revealed some interesting results. A diffraction pattern of the refined microstructure was obtained with an area of about $3 \mu \mathrm{m}^{2}$. Both Ti $\alpha$ - and $\beta$-phases were observed as well as extra reflections forming a ring near the reflection $(200) \beta$ (Fig. 6).

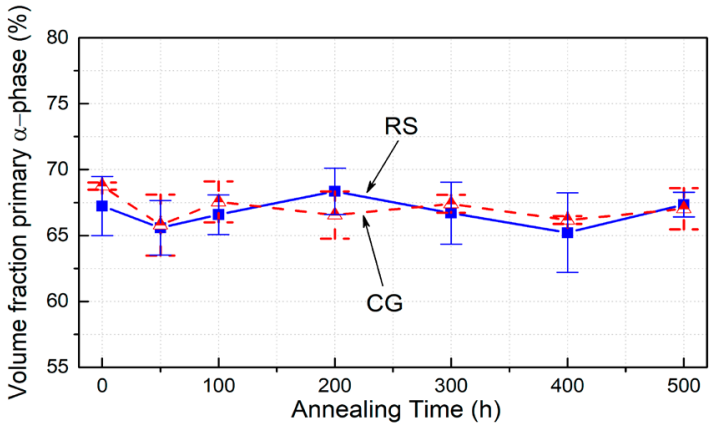

Fig 4. Volume fraction of globular $\alpha$-phase versus holding time curve for both CG and RS-processed states of VT8M-1 treated at $450^{\circ} \mathrm{C}$
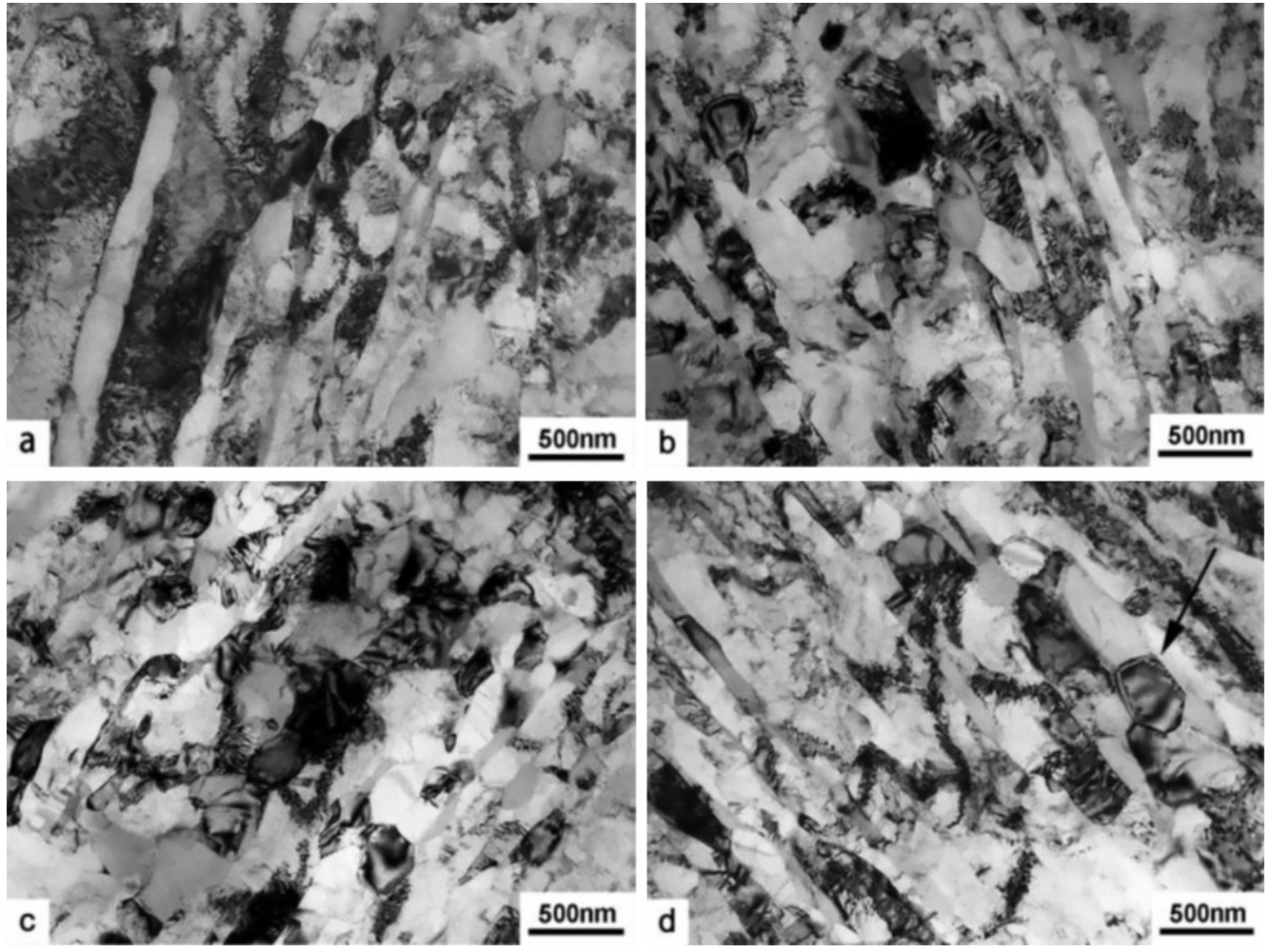

Fig. 5. TEM images of VT8M-1 samples in the longitudinal section: following RS - (a); RS + annealing at $\mathrm{T}=450^{\circ} \mathrm{C}$ for: (b) - 50h; (c) - 300h; (d) - 500h

Table 2. The Results of X-ray Analysis of VT8M-1

\begin{tabular}{|c|c|c|c|c|}
\hline State & Lattice strain, \% & Crystallite size, $\mathrm{nm}$ & Disl. density, $10^{15} \mathrm{~m}^{-2}$ & Vol. fraction of beta phase, $\%$ \\
\hline VT8M-1 CG+TT & 0.07 & 124 & 0.7 & 14.9 \\
\hline VT8M-1 HT+RS & 0.48 & 25 & 10.8 & 12.0 \\
\hline VT8M-1 HT+RS+ 50h annealing & 0.32 & 28 & 9.6 & 9.9 \\
\hline VT8M-1 HT+RS +100h annealing & 0.21 & 41 & 7.5 & 11.6 \\
\hline
\end{tabular}


It may be suggested that ageing processes caused by long-term annealing result in the precipitation of Ti-, Zr-, Si-based particles [8]. According to the literature on the subject (Hirsch), the formation of such ring-like reflections can actually point to the precipitation of a finely dispersed phase. However, we have not yet managed to accurately identify the precipitated phases. This will require some more time and a greater number of diffraction patterns.

Upon SPD, a volume fraction of $\beta$-phase in VT8M-1 decreases (Tab. 2), which relates to $\beta \rightarrow a$ transformation under the effect of large compressive stress [9].

Following long-term annealing, samples in a CG state and RS-processed were subjected to mechanical tensile tests. A long-term annealing of a CG state with a holding time of up to 300 hours resulted in a slight strengthening (Fig. 7a). At the same time, a notable reduction in a relative elongation starts only after annealing for 100 hours (Fig. 7b). The opposite situation in terms of both strength and ductility was observed after heating for 400 and 500 hours (Fig. 7a,b). This behavior can be attributed to $\beta_{0} \rightarrow a+\beta_{2}$ decay resulting from a long-term heating at $450^{\circ} \mathrm{C}$ : initial strength increase and ductility drop is conditioned by the precipitation of secondary a-phase disperse particles with further particle coagulation resulting in the opposite situation [10].

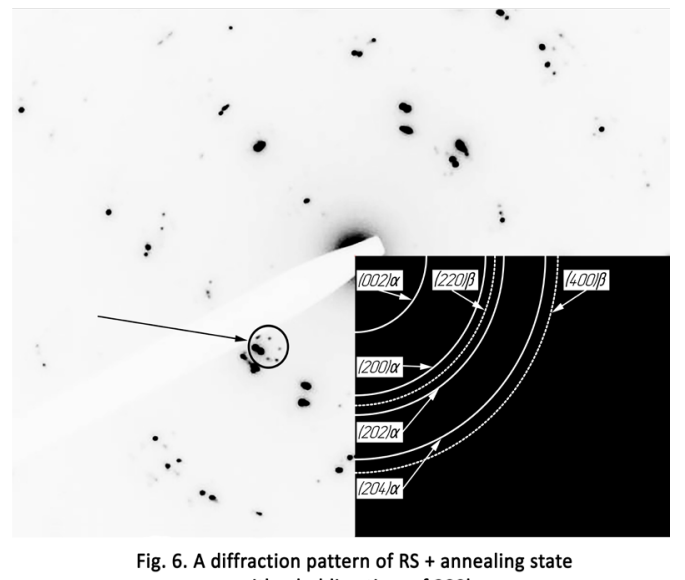

Fig. 6. A diffraction pattern of RS + annealing state with a holding time of $300 \mathrm{~h}$
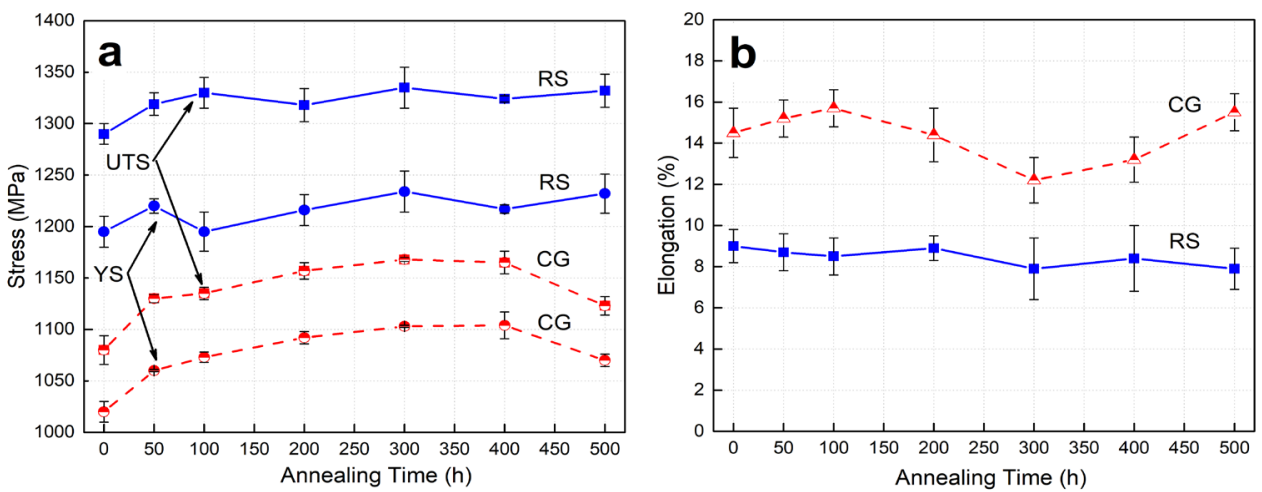

Fig. 7. The dependence of the mechanical tensile properties of VT8M-1 in the CG and RS states versus holding time from 0 to 500 hours at $450^{\circ} \mathrm{C}$ : a) ultimate tensile strength and yield strength b) elongation

The study of the thermal stability of a RS-processed state reveals slight fluctuations of ultimate stress, yield strength and relative elongation, which are within the limits of error. These minor variations, like an increase by 30-40 MPa, can be observed at the first point, following the annealing for 50 hours. This behavior is associated with the action of two competing mechanisms: namely, the strengthening in a RS-processed state (due to ageing during a long-term holding, like in a CG state) and the recovery in the strongly deformed material.

Thus, the rotary swaging results in both enhanced strength and ductility in the VT8M-1 alloy as compared to ECAP processing. Up to date, this technique is the most efficient way of producing rods on a commercial scale. High strength and thermal stability of the UFG VT8M-1 at $450^{\circ} \mathrm{C}$ open the way for successful application of the material to manufacture GTC parts.

\section{Conclusions}

The research of the effect of a duplex UFG microstructure in VT8M-1 processed via rotary swaging on the modification of its mechanical properties with an increase in a heating time up to 500 hours at $450^{\circ} \mathrm{C}$ leads to the following conclusions:

1. VT8M-1 processed by a rotary swaging preserves its thermal stability at $450^{\circ} \mathrm{C}$ after 500 hours of holding. At the same time, there has not been observed any notable change in a volume fraction of a primary $\alpha$-phase of VT8M-1 samples both for a GG state and that subjected to a rotary swaging.

2. The mechanical properties of the UFG materials change slightly due to the action of two competing mechanisms: ageing during heating at $450^{\circ} \mathrm{C}$ and the structure recovery. The yield strength of the UFG alloy at room temperature exceeds the characteristics of a CG state by 200 $\mathrm{MPa}$ and remains at the same level after long-term annealing up to 500 hours.

\section{Acknowledgments}

This work was supported by the Ministry of Education and Science of the Russian Federation under the grant of the Russian Science Foundation No. 18$79-10158$.

We would like to express our gratitude to I.Ramazanov for the performance of mechanical tests in the Shared Knowledge Center of the Nanostructured Materials and High Technologies Research and Educational Center of the Ufa State Aviation Technical University. 


\section{$\underline{\text { References }}$}

[1] Il'enko V.M., Shalin R.E. Titanovye splavy dlja aviacionnyh gazoturbinnyh dvigatelej [Titanium alloys for aircraft gas turbine engines]. Titan, 1995, № 1-2 (5-6), p.25 (in Russian).

[2] Antashev V.G., Nochovnaja N.A., Pavlova T.V., Ivanov V.I. Zharoprochnye titanovye splavy. Jelektronnyj resurs VIAM/2006-204686 [Heat-resistant titanium alloys. Electronic resource VIAM/2006-204686]. 2006. Available at: http://www.viam.ru/public (in Russian)

[3] Valiev R.Z. Nanostructuring of metals by severe plastic deformation for advanced properties. Nature Materials, 2004, V. 3, pp. 511-516.

[4] Semenova I.P., Raab G.I., Valiev R.Z. Nanostrukturnye titanovye splavy: novye razrabotki i perspektivy primenenija [Nanostructured titanium alloys: new developments and application possibility]. Nanotechnologies in Russia, 2014, Vol. 9, № 5-6 pp.79-90 (in Russian)

[5] Estrin Y., Vinogradov A. Extreme grain refinement by severe plastic deformation: A wealth of challenging science. Acta Mater. 2013, № 61, pp. 782817. https://doi.org/10.1016/j.actamat.2012.10.038

[6] Semiatin S.L. ASM Handbook: Metalworking: Bulk Forming. 2005, vol 14A, pp 179-182.

[7] Modina Iu M., Polyakov A.V., Dyakonov G.S., Yakovleva T.V., Raab A.G., Semenova I.P. Peculiarities of microstructure and mechanical behavior of VT8M-1 alloy processed rotary swaging. IOP Conf. Series: Materials Science and Engineering. 2019, № 461, pp. 1-6. doi:10.1088/1757$899 \mathrm{X} / 461 / 1 / 012056$

[8] Yang Li, Yue Chen, Jian-Rong Liu, Qing-Miao Hu, Rui Yang. Cooperative effect of silicon and other alloying elements on creep resistance of titanium alloys: insight from first-principles calculations. Scientific reports, 2016, № 6, pp. 1-8.

[9] Semenova I. P., Raab G.I., Saitova L.R., Valiev R.Z. The effect of equal-channel angular pressing on the structure and mechanical behavior of Ti-6Al4V alloy. Materials Science and Engineering: A., 2004, № 387-389, pp. 805-808.

[10] Leyens C., Peters M. Titanium and Titanium Alloys. Fundamentals and Applications. Weinheim: Wiley-VCH Verlag GmbH, 2003 , pp 513. 